\title{
Masalah Menyusui sebagai Determinan Terjadinya Risiko Depresi Postpartum pada Ibu Nifas Normal
}

\author{
Febi Sukma*, Revinel \\ Program Studi S1 Kebidanan Fakultas kedokteran dan Kesehatan \\ Universitas Muhammadiyah Jakarta \\ *Email korespondensi: febisukma@umj.ac.id
}

\section{Article Info}

Article history:

Submitted: 2020-05-15

Accepted: 2020-08-16

Published: 2020-08-30

Keywords:

Postpartum;

Depression;

Breastfeeding;

\section{ABSTRACT}

Postpartum women who had mild postpartum depression range from $10 / 1000$ live births and moderate/severe postpartum depression ranging from 30-200/1000 live births. This study aims to analyze factors that influence the risk of postpartum depression in postpartum mothers. Research Methods: This research is a quantitative study with a crosssectional design. The population in this study were postpartum women aged 2-6 weeks with 121 respondents, selected by two-stage Cluster sampling, followed by random sampling. The research was conducted at the primary health center in Central Jakarta area using the Edinburgh Postpartum Depression Scale (EPDS) questionnaire. It was found that mothers who had breastfeeding problems had a greater risk of developing postpartum depression (OR; 39.3), the greater the husband's support, the lower the risk of postpartum depression (OR; 0.13 ), and it was found that lower-income resulted in a greater risk of depression postpartum (OR; 14.7). In conclusion, the risk of post-partum depression is influenced by three factors: breastfeeding, husband support, and income. Of the three factors, the more dominant cause of postpartum depression risk is breastfeeding problems.

\section{ABSTRAK}

Kata kunci:
Nifas;
Depresi;
Menyusui;

Wanita postpartum yang mengalami depresi postpartum ringan berkisar 10/1000 kelahiran hidup dan depresi postpartum sedang/berat berkisar 30-200/1000 kelahiran hidup. Penelitian ini memiliki tujuan untuk menganalisis faktor dominan yang berhubungan dengan risiko depresi postpartum pada ibu nifas. Jenis penelitian ini adalah kuantitatif dengan teknik pengambilan sampel menggunakan metode two-stage Cluster sampling dan random sampling. Populasi dalam penelitian ini adalah ibu nifas usia 2- 6 minggu dengan besar sampel sebanyak 121 responden. Peneltian dilakukan di Puskesmas kecamatan wilayah kerja Jakarta Pusat. Sumber data menggunakan kuesioner EPDS (Edinburgh Postpartum Deppression Scale). Ditemukan ibu yang memiliki masalah menyusui berpeluang besar risiko terjadi depresi postpartum (OR; 39,3), makin besar dukungan suami maka makin rendah risiko terjadi depresi postpartum (OR; $0,13)$, dan ditemukan makin rendah penghasilan menyebabkan makin besar risiko terjadinya depresi postpartum (OR; 14,7). Disimpulkan bahwa risiko terjadi depresi postpartum dipengaruhi oleh tiga faktor yaitu masalah menyusui, dukungan suami, dan penghasilan. Dari ketiga faktor tersebut, yang lebih dominan menyebabkan risiko terjadi depresi postpartum adalah masalah menyusui. 


\section{PENDAHULUAN}

Depresi postpartum menjadi masalah kesehatan maternal yang serius, diketahui bahwa angka kematian maternal saat ini juga disebabkan oleh angka bunuh diri pada ibu postpartum, dalam Centre for Maternal and Child Enquiries (2011) yaitu sebesar $59 \%$ dari kasus bunuh diri ibu adalah karena psikosis atau depresi. ${ }^{1}{ }^{2}$ Prevalensi depresi potspartum dapat berbeda-beda di tiap negara, pada negara maju angka depresi postpartum dari 1,9\%-82,1\%, sedangkan untuk negara berkembang angka kejadian sekitar 5,2\%-74,0\%. ${ }^{3}$ Pada Skrining Edinburgh Postnatal Depression Scale (EPDS) di Kanada masih menunjukan angka yang sangat tinggi yaitu sebanyak $29 \%$. Di Qatar angka kejadian depresi postpartum yakni sebanyak $18 \%-36 \%$, sedangkan prevalensi di negara Asia berkisar 21.8\%. ${ }^{4-6}$

Depresi postpartum berdampak buruk terhadap kesehatan fisik, psikologis, hubungan social, dan perilaku negatif. Kondisi ini menurunkan minat dan ketertarikan ibu terhadap bayinya, tidak mampu merawat bayinya secara optimal termasuk menyusui, sehingga berdampak pada pertumbuhan dan perkembangan bayi. Bayi pada ibu yang depresi akan mengalami keterlambatan kognitif, psikologi, neurologi, dan perkembangan motorik. Depresi postpartum juga menimbulkan efek pada kehidupan sosial dan personal ibu seperti hubungan ibu dan pasangannya. ${ }^{7}$

Faktor penyebab depresi postpartum diantaranya adalah riwayat depresi sebelumnya, dukungan sosial, faktor ekonomi, hubungan pernikahan, faktor obstetri (sectio cesaria, persalinan dengan alat). Penelitian di Argentina menunjukan multiparitas, komplikasi perinatal, persalinan sesar, dan lama menyusui menjadi faktor risiko gejala depresi postpartum. ${ }^{8}$ Masalah menyusui juga disebutkan sebagai salah satu faktor risiko dari depresi postpartum, studi tentang nyeri puting susu terhadap aspek psikologi ibu menyusui menunjukkan bahwa nyeri puting memengaruhi terjadinya depresi pada ibu nifas..$^{9,10}$

Hasil penelitian yang dilakukan di DKI Jakarta menunjukkan $25 \%$ dari 580 ibu yang menjadi responden mengalami depresi postpartum, di RSUP Mangunkusumo Jakarta diketahui angka depresi postpartum sebesar 33\%.1112 Tingginya angka kejadian depresi postpartum menjadi dasar peneliti untuk melakukan penelitian yang telah dilakukan sebelumnya yaitu tentang faktor yang memengaruhi terjadinya risiko prediktif depresi postpartum di wilayah kerja kerja Puskesmas Jakarta Pusat. Didapatkan tiga faktor yang memengaruhi yaitu penghasilan, masalah menyusui dan dukungan suami. Dengan temuan ini peneliti tertarik untuk melanjutkan penelitian sebelumnya, untuk mengetahui determinan yang berhubungan dengan risiko terjadinya depresi postpartum pada ibu nifas normal.

\section{METODE PENELITIAN}

Metode yang digunakan dalam penelitian ini adalah penelitian kuantitatif dengan desain penelitian Cross Sectional Populasi dalam penelitian ini adalah semua ibu dengan rentang $2-6$ minggu postpartum di Puskesmas wilayah kerja Jakarta Pusat. Sampel yang diambil sebesar 121 ibu nifas dengan rumus Stanley Lameshow untuk estimasi proporsi yang jumlah populasinya tidak diketahui. ${ }^{13,14}$ Teknik pengambilan sampel dilakukan secara two-Stage Cluster sampling, yaitu pada tahap pertama dilakukan pemilihan sampel puskesmas dari semua puskesmas yang ada di wilayah kerja Jakarta Pusat. ${ }^{15}$ Puskesmas yang terpilih yaitu Puskesmas Kecamatan: Tanah Abang, Cempaka Putih, Kemayoran, dan Gambir. Selanjutnya tahap kedua dilakukan pemilihan sampel ibu nifas dari masing-masing puskesmas, secara random sampling. 
Pengumpulan data yang digunakan dalam penelitian ini dilakukan dengan mengumpulkan data primer yang sesuai dengan variabel, dan didapatkan dari pembagian kuesioner kepada ibu nifas normal $2-6$ minggu. Data primer yang didapatkan dari pengisian kuesioner EPDS. Pada kuesioner terdapat 10 pertanyaan untuk menilai risiko depresi postpartum yang terdiri dari empat alternatif jawaban yang memiliki skor 0, 1, 2, 3, 4. untuk pengukuran depresi pada ibu, dengan ketentuan apa bila skor $<10$ maka ibu nifas tidak mengalami depresi postpartum sedangkan skor $\geq 10$ maka ibu nifas mengalami depresi postpartum. ${ }^{16}$

Variabel independen menggunakan kuesioner untuk mengetahui sosio demografi ibu, meliputi ibu nifas, usia, pendidikan, paritas, jarak kehamilan, pekerjaan, penghasilan. Selain itu adapun variabel independen untuk mengetahui faktor risiko yang meliputi: komplikasi persalian, komplikasi perinatal, persalinan, pemberian ASI, masalah menyusui, dan dukungan suami.

Penelitian ini menggunakan analisis bivariat dengan uji Fisher Extact, yaitu untuk mengatasi kelemahan uji Chisquare jika sampel yang digunakan terlalu kecil $(n<20)$ dan nilai ekspektasi $<5$. Analisis data dilanjutkan dengan analisis multivariat, dengan menggunakan uji regresi logistic, yang sebelumnya dilakukan penilaian dengan uji Hosmer and Lemeshow's Goodness of Fit Test yaitu untuk menguji hipotesis nol atau tidak ada perbedaan antara data dengan model pada alpha $5 \%$ yang artinya model cocok diterapkan pada data tersebut. ${ }^{14}$

\section{HASIL PENELITIAN}

Penelitian ini dilakukan di Puskesmas Kecamatan wilayah kerja Jakarta Pusat pada periode Januari 2019. Berikut adalah hasil penelitian yang telah dilakukan:

1. Karakteristik Responden

Tabel 1 Distribusi Frekuensi Analisis Univariat berdasarkan Sosio Demografi

\begin{tabular}{lcc}
\hline Sosio Demografi & Frekuensi & Persentase (\%) \\
\hline Usia & 32 & \\
$\quad<20$ atau >35 tahun & 89 & 26,4 \\
$\quad 20-35$ tahun & & 73,5 \\
Pendidikan & 105 & 86,8 \\
$\quad$ SD-SMA & 16 & 13,2 \\
$\quad$ Pendidikan Tinggi & & \\
Paritas & 43 & 35,5 \\
$\quad$ Primipara & 78 & 64,5 \\
$\quad$ Multipara & & \\
Jarak Kehamilan & 13 & 16,4 \\
$\quad<2$ tahun & 66 & 83,5 \\
$\quad>2$ tahun & & \\
Pekerjaan & 12 & 9,9 \\
$\quad$ Bekerja & 109 & 90,1 \\
$\quad$ Tidak Bekerja & & \\
Penghasilan & 43 & 35,5 \\
$\quad<U M R$ & 78 & 64,5 \\
$\quad>U M R$ &
\end{tabular}


Pada tabel 1 sosiodemografi dari segi usia dapat dijelaskan bahwa sebagian besar usia responden adalah 20-35 tahun dengan persentase sebesar 73,5\%. Dari segi pendidikan sebagian besar pendidikan responden yaitu SD-SMA dengan persentase sebesar $86,8 \%$.

Setelah itu dari segi paritas yang terbanyak pada ibu yang multipara dengan persentase sebesar $64,5 \%$. Terdapat juga sebagiann besar responden memiliki jarak kehamilan $>2$ tahun dengan persentase sebesar $83,5 \%$. Dari segi pekerjaan sebagian besar responden yaitu tidak bekerja dengan persentase sebesar $90,1 \%$. Terakhir dari segi penghasilan sebagian besar responden berpenghasilan lebih dari UMR dengan persentase sebesar $64,5 \%$.

Tabel 2 Distribusi Frekuensi Analisis Univariat berdasarkan Faktor Risiko

\begin{tabular}{lcc}
\hline Faktor Risiko & Frekuensi & Persentase (\%) \\
\hline Komplikasi Persalinan & 16 & 13,2 \\
$\quad$ Ya & 105 & 86,8 \\
$\quad$ Tidak & 1 & 0,8 \\
Komplikasi Perinatal & 120 & 99,2 \\
$\quad$ Ya & & \\
$\quad$ Tidak & 85 & 70,2 \\
Persalinan & 36 & 29,7 \\
$\quad$ Pervaginam & & \\
$\quad$ Perabdominal & 108 & 89,3 \\
Pemberian ASI & 13 & 10,7 \\
$\quad$ Eksklusif & & \\
$\quad$ Tidak Eksklusif & 7 & 5,7 \\
Masalah Menyusui & 114 & 94,2 \\
$\quad$ Bermasalah & & \\
$\quad$ Tidak Bermasalah & 117 & 96,7 \\
Dukungan Suami & 4 & 3,3 \\
$\quad$ Mendukung & & \\
$\quad$ Tidak Mendukung & &
\end{tabular}

Sumber: Data primer, 2019

Berdasarkan tabel 2 faktor risiko dari segi komplikasi persalinan yang terbanyak sebesar $86,8 \%$ responden yang tidak memiliki komplikasi persalinan. Dari segi komplikasi perinatal yang terbanyak sebesar $99,2 \%$ responden yang tidak memiliki komplikasi. Selain itu, dari segi persalinan yang terbanyak sebesar $70,2 \%$ responden yang melahirkan pervaginal.

Dari segi pemberian ASI yang terbanyak sebesar $89,3 \%$ responden yang menyusui bayinya secara eksklusif. Dari segi masalah menyusui yang terbanyak sebesar $94,2 \%$ responden tidak bermasalah dalam menyusui. Selanjutnya dari segi dukungan suami yang terbanyak sebesar $96,7 \%$ responden yang mendapat dukungan dari suami. 
Tabel 3 Distribusi Frekuensi Analisis Univariat Berdasarkan Variabel Dependen

\begin{tabular}{lcc}
\hline Depresi Postpartum & Frekuensi & Persentase (\%) \\
\hline Risiko Prediktif $(>11)$ & 8 & 6,6 \\
Ambang Batas $(11)$ & 3 & 2,5 \\
Tidak Berisiko $(<11)$ & 110 & 90,9 \\
\hline Total & 121 & 100,0
\end{tabular}

Sumber: Data primer, 2019

Berdasarkan tabel 3 pada variabel depresi postpartum yang terbanyak sebesar $90,9 \%$ responden yang tidak memiliki risiko, disusul dengan responden yang memiliki risiko prediktif dengan persentase sebesar $6,6 \%$, dan terakhir responden yang memiliki skor diambang batas dengan persentase sebesar $2,5 \%$.

\section{Hubungan Karakteristik dengan Risiko Depresi Postpartum}

Tabel 4. Analisis Bivariat berdasarkan Sosio Demografi dan Depresi Postpartum

\begin{tabular}{|c|c|c|c|c|c|c|}
\hline \multirow{3}{*}{ Variabel } & \multicolumn{4}{|c|}{ Depresi Postpartum } & \multirow{3}{*}{$\begin{array}{c}\text { Total } \\
\mathbf{n}\end{array}$} & \multirow{3}{*}{ Nilai $p$} \\
\hline & \multicolumn{2}{|c|}{$\begin{array}{c}\text { Risiko } \\
\text { Prediktif }\end{array}$} & \multicolumn{2}{|c|}{ Tidak Berisiko } & & \\
\hline & $\mathbf{n}$ & $\%$ & $\mathbf{n}$ & $\%$ & & \\
\hline \multicolumn{7}{|l|}{ Usia } \\
\hline$<20$ atau $>35$ & 3 & 9,4 & 29 & 90,6 & 32 & \multirow{2}{*}{0,435} \\
\hline $20-35$ & 5 & 5,6 & 84 & 94,4 & 89 & \\
\hline \multicolumn{7}{|l|}{ Pendidikan } \\
\hline SD-SMA & 8 & 7,6 & 97 & 92,4 & 105 & \multirow[b]{2}{*}{0,595} \\
\hline $\begin{array}{l}\text { Pendidikan } \\
\text { Tinggi }\end{array}$ & 0 & 0,0 & 16 & 100,0 & 16 & \\
\hline \multicolumn{7}{|l|}{ Paritas } \\
\hline Primipara & 3 & 7,0 & 40 & 93,0 & 43 & \multirow{2}{*}{1,000} \\
\hline Multipara & 5 & 6,4 & 73 & 93,6 & 78 & \\
\hline \multicolumn{7}{|c|}{ Jarak kehamilan } \\
\hline$<2$ tahun & 1 & 7,7 & 12 & 92,3 & 13 & \multirow{2}{*}{1,000} \\
\hline$>2$ tahun & 4 & 6,1 & 62 & 93,9 & 66 & \\
\hline \multicolumn{7}{|l|}{ Pekerjaan } \\
\hline Bekerja & 0 & 0,0 & 12 & 100,0 & 12 & \multirow{2}{*}{1,000} \\
\hline Tidak Bekerja & 8 & 7,3 & 101 & 92,7 & 109 & \\
\hline \multicolumn{7}{|l|}{ Penghasilan } \\
\hline$<$ UMR & 7 & 14,0 & 43 & 86,0 & 50 & \multirow{2}{*}{0,008} \\
\hline$>$ UMR & 1 & 1,4 & 70 & 98,6 & 71 & \\
\hline
\end{tabular}

Pada tabel 4 sebagian besar ibu yang mengalami risiko prediktif depresi postpartum memiliki usia 20-35 tahun adalah sebanyak 5 orang (5,6\%). Hasil uji analisis dapat disimpulkan tidak terdapat hubungan bermakna antara usia ibu dengan depresi postpartum (Nilai p: 0,435). 
Pada ibu yang memiliki pendidikan SD-SMA mengalami risiko prediktif depresi postpartum adalah 8 orang $(7,6 \%)$. Hasil uji analisis didapatkan bahwa tidak terdapat hubungan bermakna antara usia ibu dengan depresi postpartum (nilai $p=0,595$ ).

Pada ibu yang memiliki paritas multipara mengalami risiko prediktif sebanyak 5 orang $(6,4 \%)$. Hasil uji statistik dapat disimpulkan bahwa tidak ada hubungan bermakna antara paritas dengan depresi postpartum (nilai $p=1,000$ ).

Pada ibu yang jarak kehamilannya $<2$ tahun mengalami risiko prediktif depresi postpartum sebanyak 1 responden (7,7\%). Hasil uji statistik dapat disimpulkan bahwa tidak ada hubungan bermakna antara paritas dengan depresi postpartum (nilai $p=1,000$ ).

Pada ibu yang tidak bekerja seluruhnya memiliki risiko postpartum sebanyak 8 orang $(7,3)$. Hasil uji statistik dapat disimpulkan bahwa tidak ada hubungan bermakna antara pakerjaan dengan depresi postpartum (nilai $\mathrm{p}=1,000$ ).

Pada ibu yang memiliki risiko prediktif postpartum sebagian besar memiliki penghasilan <UMR sebanyak 7 orang (14\%). Hasil uji statistik dapat disimpulkan bahwa ada hubungan bermakna antara paritas dengan depresi postpartum (nilai $p=0,008)$.

Tabel 5 Analisis Bivariat berdasarkan Faktor Risiko dan Depresi Postpartum

\begin{tabular}{|c|c|c|c|c|c|c|}
\hline \multirow{3}{*}{ Variabel } & \multicolumn{4}{|c|}{ Depresi Postpartum } & \multirow{3}{*}{ Total } & \multirow{3}{*}{$\underset{\mathbf{p}^{\star}}{\text { Nilai }}$} \\
\hline & \multicolumn{2}{|c|}{$\begin{array}{c}\text { Risiko } \\
\text { Prediktif } \\
\end{array}$} & \multicolumn{2}{|c|}{ Tidak Berisiko } & & \\
\hline & $\mathbf{n}$ & $\%$ & $\mathbf{n}$ & $\%$ & & \\
\hline \multicolumn{7}{|c|}{ Komplikasi Persalinan } \\
\hline Ya & 1 & $6, .3$ & 15 & 93,8 & 16 & \multirow{2}{*}{1,000} \\
\hline Tidak & 7 & 6,7 & 98 & 93,3 & 105 & \\
\hline \multicolumn{7}{|c|}{ Komplikasi Perinatal } \\
\hline $\mathrm{Ya}$ & 0 & 0 & 1 & 100,0 & 1 & \multirow{2}{*}{1,000} \\
\hline Tidak & 8 & 6,7 & 112 & 93 & 120 & \\
\hline \multicolumn{7}{|l|}{ Persalinan } \\
\hline Pervaginam & 5 & 5,9 & 80 & 94,1 & 85 & \multirow{2}{*}{0,694} \\
\hline Perabdominal & 3 & 8,3 & 33 & 91,7 & 36 & \\
\hline \multicolumn{7}{|l|}{ Pemberian ASI } \\
\hline Eksklusif & 6 & 5,6 & 102 & 94,4 & 108 & \multirow{2}{*}{0,206} \\
\hline Tidak Eksklusif & 2 & 15,4 & 11 & 84,6 & 13 & \\
\hline \multicolumn{7}{|l|}{ Masalah Menyusui } \\
\hline Bermasalah & 4 & 57,1 & 3 & 42,9 & 7 & \multirow{2}{*}{0,000} \\
\hline Tidak Bermasalah & 4 & 3,5 & 110 & 96,5 & 114 & \\
\hline \multicolumn{7}{|l|}{ Dukungan Suami } \\
\hline Mendukung & 6 & 5,1 & 111 & 94,9 & 117 & \multirow{2}{*}{0,020} \\
\hline Tidak Mendukung & 2 & 50,0 & 2 & 50,0 & 4 & \\
\hline
\end{tabular}

Pada tabel 5 sebagian besar ibu yang memiliki risiko prediktif depresi postpartum tidak memiliki komplikasi pada persalinan sebanyak $6,7 \%$. Hasil uji statistik dapat disimpulkan bahwa tidak ada hubungan bermakna antara komplikasi persalinan dengan depresi (nilai $p=1,000$ ). 
Pada ibu yang tidak memiliki komplikasi perinatal mengalami risiko prediktif depresi postpartum sebanyak 8 orang $(6,7 \%)$. Hasil uji statistik dapat disimpulkan bahwa tidak ada hubungan bermakna antara komplikasi perinatal dengan depresi postpartum (nilai $\mathrm{p}=1,000$ ). Ibu yang bersalin secara normal mengalami risiko prediktif depresi postpartum sebanyak 5 orang $(5,88 \%)$. Hasil uji statistik dapat disimpulkan bahwa tidak ada hubungan bermakna antara komplikasi perinatal dengan depresi postpartum (nilai $\mathrm{p}=0,694$ ).

Ibu yang memberikan ASI secara eksklusif mengalami risiko prediktif depresi postpartum sebanyak 6 orang (5,6\%). Hasil uji statistik dapat disimpulkan bahwa tidak ada hubungan bermakna antara pemberian ASI secara eksklusif dengan depresi postpartum (nilai $\mathrm{p}=0,206$ ). Ibu yang memiliki masalah menyusui mengalami risiko prediktif depresi postpartum sebanyak 4 orang $(57,10 \%)$. Hasil uji statistik dapat disimpulkan bahwa ada hubungan bermakna antara masalah menyusui dengan depresi postpartum (nilai $\mathrm{p}=0,000$ ).

Ibu yang tidak mendapat dukungan suami mengalami risiko prediktif depresi postpartum sebanyak 2 orang $(50,0 \%)$. Hasil uji statistik dapat disimpulkan bahwa ada hubungan bermakna antara dukungan suami dengan depresi postpartum (nilai $\mathrm{p}=0,020)$.

\section{Determinan yang Berhubungan dengan Risiko Depresi Postpartum}

Tabel 6. Hasil Uji Hipotesis dengan Regresi Logistik

\begin{tabular}{lcccccc}
\hline \multicolumn{1}{c}{ Variabel } & B & SE & Wald & P-Value & Kesimpulan & OR \\
\hline Masalah Menyusui & 3,7 & 1,3 & 8,1 & 0,004 & Tolak HO & 39,2 \\
Dukungan Suami & 1,9 & 2,7 & 0,6 & 0,45 & Terima H0 & 0,1 \\
Penghasilan & 2,7 & 1,3 & 4,4 & 0,03 & Tolak HO & 14,7 \\
Konstanta & 1,2 & 1,2 & 0,8 & 0,9 & - & 0,3 \\
\hline
\end{tabular}

Hasil analisis menunjukkan koefisien positif sebesar 3,7 dengan nilai OR sebesar 39,2 artinya ibu yang memiliki masalah menyusui dapat risiko terjadi depresi postpartum sebesar 39,2 kali lebih besar daripada ibu yang tidak memiliki masalah menyusui. Koefisien positif menandakan arah hubungan yang searah yaitu semakin parah masalah menyusui yang diderita oleh ibu maka akan semakin besar peluang risiko terjadi depresi postpartum.

Hasil analisis menunjukkan koefisien sebesar 1,9 dengan nilai OR sebesar 0,1 artinya suami yang memberi dukungan penuh ke sang ibu dapat risiko terjadi depresi postpartum 0,1 kali daripada suami yang tidak memberi dukungan ke sang ibu. Koefisien negatif menandakan arah hubungan yang berlawanan arah yaitu semakin besar dukungan yang diberikan suami ke ibu akan semakin kecil peluang risiko terjadi depresi postpartum.

Hasil analisis menunjukkan koefisien positif sebesar 2,7 dengan nilai OR sebesar 14,7 artinya penghasilan dengan kategori dibawah UMR dapat risiko terjadi depresi postpartum sebesar 14,7 kali lebih besar dari pada penghasilan dengan kategori di atas UMR. Koefisien positif menandakan arah hubungan yang searah yaitu semakin jauh penghasilan dibawah UMR akan semakin besar peluang risiko terjadi depresi postpartum. Pada tabel 3 variabel yang memiliki nilai OR terbesar adalah variabel masalah menyusui sehingga masalah menyusui adalah variabel yang paling berhubungan dalam memprediksi ibu yang risiko terjadi depresi postpartum. 


\section{PEMBAHASAN}

Pada penelitian ini dari faktor sosiodemografi menunjukkan bahwa terdapat hubungan yang tidak signifikan antar usia ibu (nilai $p=0,435$ ), pendidikan (nilai $p=0,595$ ), paritas (nilai $p=1,000$ ), jarak kehamilan (nilai $p=1,000$ ), dan pekerjaan (nilai $\mathrm{p}=1,000$ ) dengan risiko kejadian depresi postpartum. Penelitian ini didukung dengan penelitian yang dilakukan oleh Kusumawati, Astuti dan Hendriyati di Klaten yang menunjukkan bahwa usia, tingkat pendidikan, paritas dan jenis pekerjaan tidak memiliki hubungan yang signifikan dengan kejadian depresi postpartum. ${ }^{17}$

Pada penelitian ini juga didukung dengan penelitian yang dilakukan oleh Upadhyay, et al (2017) di India yang menunjukkan bahwa tidak ada hubungan yang signifikan antara usia dengan depresi postpartum. ${ }^{18}$ Selanjutnya, penelitian yang dilakukan di Nigeria juga menyebutkan bahwa tidak ada hubungan yang signifikan antara usia ibu dan pendidikan. ${ }^{19}$

Pada faktor risiko ini didapatkan hasil bahwa tidak ada hubungan yang signifikan antara komplikasi persalinan (nilai $p=1,000$ ), komplikasi perinatal (nilai $p=1,000$ ), jenis persalinan (nilai $p=0,694$ ), dan pemberian $A S I$ (nilai $p=0,206$ ) dengan risiko terjadinya depresi postpartum. Penelitian ini berbanding terbalik dengan penelitian di Jepang yang tertulis dalam jurnal milik Mathisen et al (2013) yang menyebutkan bahwa dari 627 ibu yang dengan score EPDS tinggi memiliki hubungan yang signifikan dengan melahirkan prematur dan komplikasi persalinan. ${ }^{8}$

Berdasarkan jenis persalinan, penelitian ini berbanding terbalik dengan penelitian yang dilakukan oleh Mathisen (2013) di Argentina yang menunjukkan hubungan yang signifikan antara persalinan sesar dengan risiko terjadinya depresi postpartum. ${ }^{8}$ Pada penelitian yang dilakukan oleh Carter et al (2006) dari 24 studi yang ia lakukan, terdapat 5 yang menyebutkan bahwa terdapat hubungan antara depresi postpartum dan jenis persalinan, 15 menunjukkan tidak adanya hubungan dan 4 yang lain mengdapatkan hasil campuran. Carter (2006) menyebutkan bahwa persalinan sesar merupakan faktor risiko yang lemah dan perlu diperhatkan pula dari aspek lain seperti persalinan sesar yang direncanakan atau yang tidak direncanakan, dan tingkat kontrol ibu dalam menjalani prosedur. ${ }^{20}$

Hasil analisis data multivariat didapatkan tiga faktor yang menyebabkan terjadinya risiko depresi postpartum, yaitu penghasilan, dukungan suami, dan masalah menyusui. Pada variabel penghasilan, menunjukkan bahwa penghasilan dengan kategori dibawah UMR, peluang risiko terjadi depresi postpartumnya lebih besar daripada penghasilan dengan kategori diatas UMR. Sejalan dengan penelitian yang dilakukan oleh Upadhyay, et al (2017) di India yang menunjukkan bahwa penghasilan dengan depresi postpartum memiliki hubungan yang signifikan. Hal ini disebabkan karena ibu yang memiliki penghasilan rendah biasanya mendapatkan pelayanan kesehatan yang rendah pula. Penghasilan juga berpengaruh langsung dengan kebutuhan dan perawatan biaya bayi, sehingga ibu cenderung merasa tertekan dengan adanya perubahan tersebut. ${ }^{18}$

Rendahnya penghasilan ini juga merupakan tekanan yang signifikan bagi para suami, karena perubahan peran menjadi suami merupakan tantangan tersendiri, diantaranya perubahan akan rasa tanggungjawab finansial sebagai kepala keluarga. Peralihan peran merupakan stressor tersendiri bagi para suami yang dapat menyebabkan kelelahan, sensitif dan frustrasi, bahkan lari dari kondisi dengan bekerja lebih lama, sedangkan ibu di rumah membutuhkan dukungan suami menyebabkan tekanan tersendiri bagi ibu. Itulah mengapa komunikasi antar pasangan menjadi penting dimasa peralihan peran ini. Tenaga kesehatan juga berperan dalam situasi ini, 
yaitu diantaranya memberikan kesempatan pada ibu terlebih suami untuk mengungkapkan kesulitan atau emosinya pada masa transisi ini. ${ }^{21}$

Dikatakan bahwa suami yang mendukung ibu secara emosional memungkinkan dirinya untuk mengungkapkan perasaan dan masalahnya, sehingga memudahkan pasangan untuk menemukan penyelesain masalah bersama. Kondisi ini berdampak positif hingga timbul rasa percaya diri dan dihargai pada ibu, dan mengurangi peluang terjadi depresi postpartum. Penelitian Nurfatimah dan Entoh, (2018) menyebutkan dukungan memberi pengaruh dalam mengurangi depresi yang dihadapi wanita pada masa postpartum. lbu pospartum yang merasa dihargai, diperhatikan dan dicintai oleh suami dan keluarganya tentunya tidak akan merasa diri kurang berharga. ${ }^{22,23}$

Masalah menyusui menjadi permasalahan umum yang mungkin terjadi pada awal masa nifas, pada temuan uji multivariat didapatkan bahwa kemungkinan terjadi depresi postpartum pada ibu yang memiliki masalah menyusui berisiko tiga puluh sembilan kali lebih besar dibandingkan pada ibu yang tidak memiliki masalah menyusui. Banyak studi yang menunjukkan bahwa menyusui berdampak pada psikologis ibu postpartum. Mathisen, et al (2013) di Argentina dan penelian Zubaran et al (2013) di Brazil menunjukkan bahwa terdapat hubungan antara pemberian ASI dengan depresi postpartum. ${ }^{8,24}$ Didukung dengan penelitian yang dilakukan di Kanada menyebutkan salah satu penyebab terjadinya depresi postpartum adalah masalah dalam menyusui. ${ }^{25}$

Puting susu lecet, kesulitan memberikan ASI, ASI sedikit, atau tidak keluar merupakan masalah yang sering terjadi pada awal masa nifas. Tujuh ibu yang memiliki masalah dalam menyusui dua diantaranya mengeluh putingnya lecet dan lima lainnya mengeluh ASI nya sedikit. Penelitian oleh Amir LH et al (1996) yang menyebutkan bahwa nyeri pada puting saat menyusui dapat memengaruhi psikologis ibu. ${ }^{26}$ Depresi sendiri biasanya juga dapat memengaruhi kesulitan dalam pemberian ASI sehingga ibu sering mengeluh ASI yang diberikan sedikit atau bahkan ASI tidak keluar (Hamel, et al. 2019) ${ }^{25}$.

Puting susu lecet bagi ibu menyusui merupakan kondisi yang sangat menyakitkan, kurangnya pengetahuan dan dukungan akan menyebabkan ibu salah langkah dalam mengatasi masalah menyusui ini. Pada umumnya ibu dengan puting susu lecet memutuskan untuk menghentikan menyusui langsung dan mulai memberikan ASI perah pada bayi dengan meggunakan dot. Penggunaan dot pada bayi menimbulkan masalah baru dengan adanya bingung puting, yang menyebabkan bayi menolak menyusu langsung setelah puting sudah pulih. Selain itu praktik pemberian susu dengan dot meningkatkan risiko kontaminasi bakteri yang bisa menyebabkan diare pada anak. Bayi yang menolak menyusu dan berakhir dengan penyapihan dini akan meningkatkan risiko kecemasan hingga depresi postpartum. ${ }^{9,27}$

Menghadapi masalah menyusui merupakan masalah yang sangat menantang pada awal menjadi orangtua, disinilah peran tenaga kesehatan untuk mempersiapkan pengetahuan ibu untuk menghadapi masalah menyusui yang dimulai sejak kehamilan dan dilanjutkan hingga masa nifas. Keberhasilan menyusui memerlukan dukungan sosial, maka pendidikan persiapan menyusui tidak bisa difokuskan hanya pada ibu, tapi juga untuk suami ataupun seluruh keluarga yang ada di dekat ibu. ${ }^{28}$ 


\section{SIMPULAN DAN SARAN}

Risiko terjadi depresi postpartum disebabkan oleh tiga faktor yaitu masalah menyusui, dukungan suami, dan penghasilan, dengan masalah menyusui sebagai faktor paling dominan dari ketiga faktor tersebut. Dari penelitian ini diharapkan menjadi masukan bagi ibu nifas, dan pasangan untuk mempersiapkan diri dalam menghadapi masa nifas, diantaranya peningkatan pendidikan kesehatan laktasi untuk mengurangi masalah yang mungkin terjadi dalam menyusui. Dukungan suami dapat ditumbuhkan sejak masa kehamilan dengan ikut serta dalam pemeriksaan kehamilan dan mengikuti kelas hamil. Tenaga kesehatan sangat berperan penting dalam pencegahan dan deteksi dini risiko depresi postpartum, maka hasil penelitian yang telah diberikan kepada pihak Puskesmas diharapkan dapat menjadi masukan bagi tenaga kesehatan dalam membantu ibu dan pasangan dalam menghadapi masa nifas.

\section{UCAPAN TERIMA KASIH}

Penelitian menyampaikan terima kasih kepada Dekan Fakultas Kedokteran dan Kesehatan Universitas Muhammadiyah Jakarta, Dr., dr Muhammad Fachri, SpP, FAPSR, FISR yang telah memberikan dukungan dana penelitian. Ibu Hamidah., SST., MKM selaku Ketua Program Studi Sarjana Kebidanan yang selalu memberikan semangat meneliti. Suku Dinas Kesehatan dan Puskesmas Kecamatan Wilayah Jakarta Pusat yang memberikan izin sehingga penelitian ini dapat berjalan. Para ibu nifas yang bersedia sebagai responden sehingga penelitian ini dapat terlaksana.

\section{DAFTAR PUSTAKA}

1. Kimmel M. Maternal Mental Health Matters. N C Med J. 2020;81(1):45-50.

2. Wilkinson H. Saving Mothers' Lives. Reviewing Maternal Deaths to Make Motherhood Safer: 2006-2008. BJOG An Int J Obstet Gynaecol. 2011 Oct;118(11):1402-3.

3. Norhayati MN, Nik Hazlina NH, Asrenee AR, Wan Emilin WMA. Magnitude and risk factors for postpartum symptoms: A literature review. J Affect Disord. 2015;175:34-52.

4. Lanes A, Kuk JL, Tamim H. Prevalence and characteristics of Postpartum Depression symptomatology among Canadian women: A cross-sectional study. BMC Public Health. 2011;11(1):302.

5. Burgut FT, Bener A, Ghuloum S, Sheikh J. A study of postpartum depression and maternal risk factors in Qatar. J Psychosom Obstet Gynecol. 2013;34(2):90-7.

6. Roomruangwong C, Epperson CN. Perinatal depression in Asian women: Prevalence, associated factors, and cultural aspects. Asian Biomed. 2011;5(2):179-93.

7. Slomian J, Honvo G, Emonts $P$, Reginster JY, Bruyère $O$. Consequences of maternal postpartum depression: A systematic review of maternal and infant outcomes. Vol. 15, Women's Health. 2019.

8. Mathisen S, Glavin K, Lien L, Lagerløv P. Prevalence and Risk Factors for Postpartum Depressive Symptoms in Argentina: A Cross- Sectional Study. Int J Womens Health. 2013 Nov;787.

9. Buck ML, Amir LH, Cullinane M, Donath SM. Nipple Pain, Damage, and Vasospasm in the First 8 Weeks Postpartum. Breastfeed Med. 2014;9(2):56-62.

10. Pope CJ, Mazmanian D. Breastfeeding and postpartum depression: An overview and methodological recommendations for future research. Depress Res Treat. 2016;2016.

11. Alfiben. Efektifitas Peningkatan Dukungan Suami dalam Menurunkan Terjadinya Depresi Postpartum. Maj Obstet Ginaecology Indones. 2011;24(4).

12. Soep. Pengaruh Intervensi Psikoedukasi Dalam Mengatasi Depresi Postpartum Di RSU Dr. Pirngadi Medan. Universitas Indonesia; 2011.

13. Lemeshow S, David J. Besar Sampel dalam Penelitian Kesehatan (terjemahan). Yogyakarta: Gadjah Mada University Press; 1997. 
14. Dahlan S. Statistik untuk Kedokteran dan Kesehatan. Jakarta: Salemba Medika; 2011.

15. Notoatmodjo S. Metodologi Penelitian Kesehatan. Jakarta: Rineka Cipta;

16. Fraser DM, Cooper MA. Myles Buku Ajar Bidan. 14th ed. Oxford: EGC; 2003. 645 p.

17. Kusumastuti DPA, Hendriyati S. Hubungan Karakteristik Individu dengan Depresi Postpartum di Rumah Sakit Umum Daerah Kebupaten Kebumen. J Involusi Kebidanan. 2015;5(9):1-17.

18. Upadhyay RP, Chowdhury R, Aslyeh Salehi, Sarkar K, Singh SK, Sinha B, et al. Postpartum Depression in India: A Systematic Review and Meta-Analysis. Bull World Health Organ. 2017 Oct;95(10):706-717C.

19. Agbaje OS, Anyanwu JI, Umoke PIC, Iwuagwu TE, Iweama CN, Ozoemena EL, et al. Depressive and Anxiety Symptoms and Associated Factors among Postnatal Women in Enugu-North Senatorial District, South-East Nigeria: a Cross-Sectional Study. Arch Public Heal. 2019 Dec;77(1):1.

20. Carter FA, Frampton CMA, Mulder RT. Cesarean Section and Postpartum Depression: a Review of the Evidence Examining the link. Psychosom Med. 2006;68(2):321-30.

21. Baldwin S, Malone M, Sandall J, Bick D. Mental Health and Wellbeing during the Transition to Fatherhood. JBI Database Syst Rev Implement Reports. 2018 Nov;16(11):2118-91.

22. Nurfatimah N, Entoh C. Hubungan Faktor Demografi dan Dukungan Sosial dengan Depresi Pascasalin. J Profesi Med J Kedokt dan Kesehat. 2018 May;11(2).

23. Marmer LW, Ariana AD. Persepsi terhadap Dukungan Suami pada Primipara yang Mengalami Depresi Pasca Melahirkan. J Psikol Klin dan Kesehat Ment. 2016;5(1).

24. Zubaran C, Foresti K. The Correlation Between Breastfeeding Self-Efficacy and Maternal Postpartum Depression in Southern Brazil. Sex Reprod Healthc. 2013 Mar;4(1):9-15.

25. Hamel C, Lang E, Morissette K, Beck A, Stevens A, Skidmore B, et al. Screening for depression in women during pregnancy or the first year postpartum and in the general adult population: a protocol for two systematic reviews to update a guideline of the Canadian Task Force on Preventive Health Care. Syst Rev. 2019 Dec;8(1):27.

26. Amir LH, Dennerstein L, Garland SM, Fisher J, Farish SJ. Psychological Aspects of Nipple Pain in lactating Women. J Psychosom Obstet Gynecol. 1996 Jan;17(1):53-8.

27. Nasrul N, Hafid F, Ramadhan K, Suza DE, Efendi F. Factors associated with bottle feeding in children aged 0-23 months in Indonesia. Child Youth Serv Rev. 2020;116(July):0-4.

28. Pålsson P, Kvist LJ, Ekelin M, Hallström IK, Persson EK. “I Didn't Know What to Ask About": First-Time Mothers' Conceptions of Prenatal Preparation for the Early Parenthood Period. J Perinat Educ. 2018;27(3):163-74. 